Nota

\title{
FORMAÇÃO DE RAMOS ADVENTÍCIOS A PARTIR DE ESPINHOS EM LIMOEIRO ‘VOLKAMERIANO' TRATADOS COM ÁCIDO GIBERÉLICO (1)
}

\author{
EMANUEL MAIA $\left({ }^{2 *}, 4\right)$; DALMO LOPES DE SIQUEIRA $\left({ }^{2}\right)$; ANTÔNIO RESENDE FERNANDES $\left({ }^{3}\right)$
}

\begin{abstract}
RESUMO
As giberelinas afetam numerosos processos do desenvolvimento das plantas, incluindo a morfogênese. A formação de gemas axilares e seu desenvolvimento após a aplicação de ácido giberélico (GA) em plantas deficientes em sua síntese são conhecidos, contudo, a formação de ramos adventícios a partir de espinhos em citros ainda não havia sido registrada. Desta forma, o presente trabalho teve como objetivo, relatar pela primeira vez, a formação de ramos adventícios a partir de espinhos de plantas jovens em limoeiro 'Volkameriano' após a pulverização de $\mathrm{GA}_{3}$.
\end{abstract}

Palavras-chave: Citrus volkameriana, giberelinas, diferenciação, brotações, espinhos.

\section{ABSTRACT \\ MORPHOLOGICAL CHANGES IN `VOLKAMERICANO’ LEMON TREES SPRAYED WITH GIBBERELLIC ACID}

Gibberellins affect a several of development processes of plants. The formation of axillary buds and their development upon the gibberellic acid (GA) application on plants deficient in its synthesis are known. However the formation of adventitious branches from thorns in Citrus still were not reported. Thus, the objective of this work was to report for the first time the formation of adventitious branches from thorns of young "Volkamericano" lemon plants after treatment with $\mathrm{GA}_{3}$.

Key words: Citrus volkamericana, gibberellins, differentiation, sprouting, thorns.

$\left({ }^{1}\right)$ Recebido para publicação em 13 de fevereiro e aceito em 13 de outubro de 2008.

$\left({ }^{2}\right)$ Departamento de Fitotecnia, Setor de Fruticultura, Universidade Federal de Viçosa, UFV, 36570-000 Viçosa (MG), Brasil. E-mail: emanuelfms@gmail.com ${ }^{*}$ ) Autor correspondente; siqueira@ufv.br

$\left.{ }^{3}\right)$ Escola Agrotécnica Federal de Santa Teresa, Rodovia ES 080, km 22, 29660-000 Santa Teresa (ES), Brasil. E-mail: resende@eafst.gov.br

$\left({ }^{4}\right)$ Bolsista CNPq. 


\section{Introdução}

Os efeitos causados pelo ácido giberélico nas plantas são amplamente conhecidos e discutidos na literatura e, em geral, promovem o alongamento axial de órgãos como caules, pecíolos e inflorescências (FLeEt e Sun, 2005; SWAin e Singh, 2005), além de causar alterações funcionais de tecidos não diferenciados como, por exemplo, na formação de embriões, gemas e/ ou ramos adventícios, espinhos ou folhas (MAUSETH, 1977; Mapelli e Kinet, 1992; Ezura e Harberd, 1998; VReugdenhil et al., 1998; DeMason, 2005; FleEt e Sun, 2005; Shani et al., 2006). Apesar da aplicação de giberelinas em plantas com espinhos, como cactáceas e citros, não foram encontrados relatos de alterações funcionais de espinhos em ramos adventícios (Mauseth, 1977; Boyle e Marcotrigiano, 1997; Modesto et al., 1999, RAmos-Hurtado et al., 2006; FAGOAGa et al., 2007).

Este trabalho teve por objetivo relatar, pela primeira vez, a modificação funcional de espinhos em ramos adventícios em plantas jovens de limoeiro 'Volkameriano' (Citrus volkameriana Tem \& Pasq.) após a aplicação de foliar de ácido giberélico.

Com o objetivo de avaliar o efeito do paclobutrazol sobre o crescimento do limoeiro 'Volkamericano' (Citrus volkameriana Tem \& Pasq.), este experimento foi desenvolvido no período de julho de 2002 a março de 2003, em casa de vegetação, seguindo o esquema fatorial $4 \times 2$, com quatro concentrações de paclobutrazol $(0,75,150$ e $225 \mathrm{mg}$ de i.a. planta $\left.{ }^{-1}\right)$ e duas concentrações de ácido giberélico (0 e $20 \mathrm{mg}$ do i.a. $\mathrm{dm}^{-3}, \mathrm{GA}_{3}$ ). Foi adotado o delineamento em blocos casualizados com quatro repetições, e como unidade experimental cinco plantas de limoeiro 'Volkamericano', com seis meses de idade e aproximadamente $32 \mathrm{~cm}$ de altura (FERNANDES, 2004). Durante o período experimental não houve controle das condições ambientais dentro casa de vegetação e as médias das temperaturas máximas e mínimas foram $36,1 \pm 3,1$ e $19,0 \pm 1,2{ }^{\circ} \mathrm{C}$ respectivamente.

O paclobutrazol (PACHLOBUTRAZOL 100 CE, com $10 \%$ de i.a. WISER Imp. Serv. Exp. e Repres. Ltda.) foi aplicado individualmente no substrato de cada planta, em aplicação única com volume de 50 $\mathrm{cm}^{3}$. O ácido giberélico (PRO-GIBB, com $10 \%$ i.a., Abbott Laboratories) foi aplicado em quatro pulverizações foliares com intervalos de dez dias, iniciando no mesmo dia que a aplicação do paclobutrazol. Foi adicionado às soluções de ácido giberélico pulverizadas, espalhante adesivo à base de copolímero de poliéster e silicone, na razão de $1 \mathrm{~cm}^{3}$ $\mathrm{dm}^{-3}$. A partir do início da aplicação dos tratamentos, as irrigações foram efetuadas diretamente no substrato de cada planta, para evitar uma possível lavagem do $\mathrm{GA}_{3}$ aplicado nas folhas. Aos 50 dias após a aplicação dos produtos, as plantas que estavam com espinhos modificados em ramos foram observadas, quantificadas e registradas fotograficamente.

Em todas as plantas que receberam as pulverizações foliares com $20 \mathrm{mg} \mathrm{dm}^{-3}$ de $\mathrm{GA}_{3}$ foram constatados espinhos que se transformaram em ramos laterais; no entanto, estas modificações não foram observadas nos demais tratamentos. Observou-se que, inicialmente, o espinho duplicava seu ápice, e desta divisão uma parte assumia a dominância, produzindo ramos aparentemente normais (Figura 1). Não foram avaliados o número de espinhos por planta que se modificaram em ramos laterais e as alterações anatômicas que ocorreram nestes órgãos.

Os efeitos das giberelinas são variáveis sobre a formação de novas gemas. Em cultivo in vitro de plantas mutantes de Arabidopsis thaliana, com menores níveis endógenos ou menos responsivas às giberelinas, a regeneração de gemas vegetativas foi maior que nas plantas silvestres (controles), e a aplicação de paclobutrazol nas plantas silvestres aumentou a formação de novas gemas vegetativas (EzURA e HARBERD, 1995). Em modelos que descrevem a regulação da atividade meristemática, observa-se que a manutenção do meristema apical requer baixos níveis de giberelinas e estes níveis dependem da expressão de genes que reduzem a biossíntese de precursores de giberelinas (JASINSKI et al., 2005; SHANI et al., 2006).

Por outro lado, a aplicação de $\mathrm{GA}_{3}$ no meio de cultura foi relatada como indutora da formação de embriões adventícios na regeneração de tecidos de ovários não polinizados de mamoeiro papaya (Тикимото et al., 2000). Verificaram-se em segmentos de ramas de batatas cultivados em meio com $8 \%$ de sacarose (altas concentrações de sacarose são indutoras da formação de tubérculos) e em uma mistura de $\mathrm{GA}_{4 / 7}$ o desenvolvimento de gemas axilares em estolões (VReugdenhil et al., 1998). A supressão de genes que inibem a biossíntese das giberelinas em batatas resultou na formação de tubérculos a partir de gemas axilares (Rosin et al., 2003). Também foi reportado que em genótipos de ervilha deficientes na produção de giberelinas (em que não havia gavinhas no ápice de suas ramas, uni-tac), a aplicação de $G_{1}$ e $G_{3}$ resultou na conversão do folíolo terminal em gavinhas, (DeMAson, 2005). Após a aplicação de $\mathrm{GA}_{3}$ em mutantes de tomateiro (torosa2), com forte inibição da formação de gemas axilares, foi observado um incremento na produção de gemas axilares e seu posterior desenvolvimento em brotações laterais (MAPELI e KINET, 1992). 


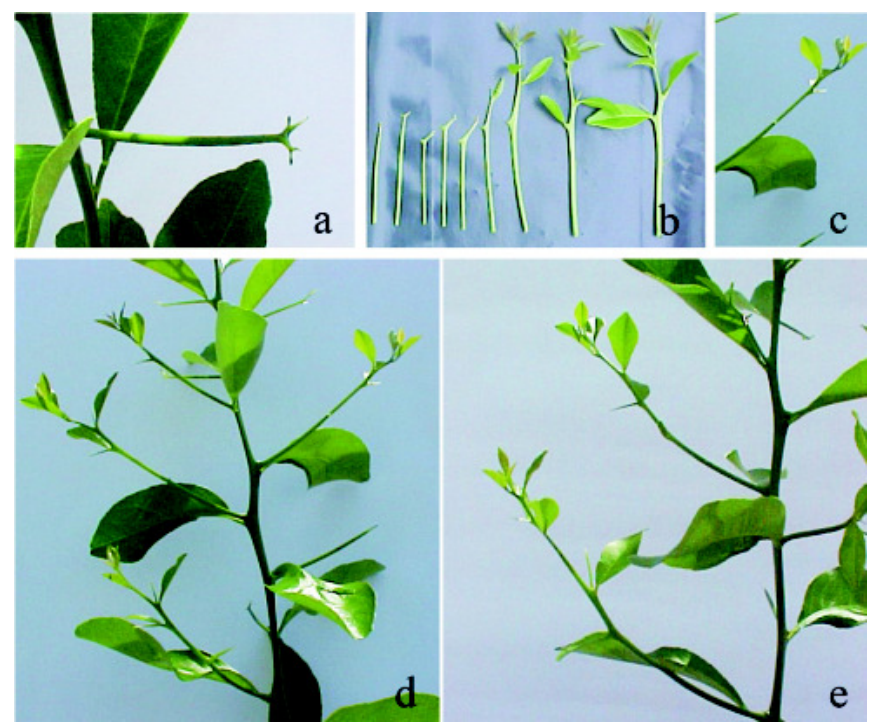

Figura 1. Modificações em espinhos causados pela aplicação de ácido giberélico $\left(\mathrm{GA}_{3}\right)$ em mudas jovens de limoeiro 'Volkameriano'. (a) Fase inicial da diferenciação. (b) Sequência da diferenciação dos espinhos em ramos. (c-e) Novos ramos formados a partir de espinhos.

Em conclusão, os processos que proporcionaram as alterações funcionais ocorridas nos espinhos de ramos de limoeiro 'Volkameriano' são desconhecidos, porém o conhecimento atual proporciona evidências que a alteração promovida pela aplicação exógena de $\mathrm{GA}_{3}$ no balanço de giberelinas nas células dos ápices dos espinhos pode ter proporcionado as modificações observadas.

\section{REFERÊNCIAS}

BOYLE, T.H.; MARCOTRIGIANO, M. Influence of benzyladenine and gibberellic acid on organogenesis in 'Crimson Giant' Easter cactus. Plant Growth Regulation, Dordrecht, v.22, p.131-136, 1997.

DEMASON, D.A. Auxin-cytokinin and auxin-gibberellin interactions during morphogenesis of the compound leaves of pea (Pisum sativum). Planta, Bonn, v.222, n.1, p.151-166, 2005.

EZURA, H; HARBERD, N.P. Endogenous gibberellin levels influence in-vitro shoot regeneration in Arabidopsis thaliana (L.) Heynh. Planta, Bonn, v.197, n.2, p.301-305, 1995.

FAGOAGA, C.; R. TADEO, F.R.; IGLESIAS, D.J.; HUERTA, L.; LLISO, I.; VIDAL, A.M.; TALON, M.; NAVARRO, L.; GARCÍAMARTÍNEZ, J.L.; PENAA, L. Engineering of gibberellin levels in citrus by sense and antisense overexpression of a GA 20oxidase gene modifies plant architecture. Journal of Experimental Botany, Oxford, v.58, 1407-1420, 2007
FERNANDES, A.R. Crescimento do limoeiro 'Volkameriano' tratado com paclobutrazol e ácido giberélico. 2004. 50p. Dissertação (Mestrado em Fitotecnia) - Universidade Federal de Viçosa, Viçosa.

FLEET, C.M.; SUN, T-p. A DELLAcate balance: the role of gibberellin in plant morphogenesis. Current Opinion in Plant Biology, London, v.8, p.77-85, 2005.

JASINSKI, S.; PIAZZA, P.; CRAFT,J.; HAY, A.; WOOLLEY, L.; RIEU, I.; PHILLIPS, A.; HEDDEN, P.; TSIANTIS, M. KNOX action in arabidopsis is mediated by coordinate regulation of cytokinin and gibberellin activities. Current Biology, London, v.15, p.1560-1565, 2005.

MAPELLI, S.; KINET, J.M. Plant growth regulator and graft control of axillary bud formation and development in the TO2 mutant tomato. Plant Growth Regulation, Dordrecht, v.11, n.4, p.385-390, 1992.

MAUSETH J.D. Cytokinin- and gibberellin acid-induced effects on the determination and morphogenesis of leaf primordia in Opuntia polyacantha (Cactaceae). American Journal of Botany, Baltimore, v.64, n.3, p.337-346, 1977.

MODESTO, J.C.; RODRIGUES, J.D.; PINHO, S.Z. Ácido giberélico e o desenvolvimento de plântulas de tangerina 'Cleópatra' (Citrus reshni Hort. ex. Tanaka), Scientia Agricola, Piracicaba, v.56, n.2, 1999.

RAMOS-HURTADO, A.M.; KOLLER, O.C.; MARIATH, J.A.; SARTORI, I.A.; THEISEN, S.; REIS, B. Diferenciação floral, alternância de produção e uso de ácido giberélico em tangerineira 'Montenegrina' (Citrus deliciosa Tenore). Revista Brasileira de Fruticultura, Jaboticabal, v.28, n.3, p.355-359, 2006.

ROSIN, F.M.; HART, J.K.; HORNER H.T.; DAVIES P.J.; HANNAPEL, D.J.; Overexpression of a Knotted-like homeobox gene of potato alters vegetative development by decreasing gibberellin accumulation. Plant Physiology, Bethesda, v.132, p.106-117, 2003.

SHANI, E.; YANAI, O.; ORI, N. The role of hormones in shoot apical meristem function. Current Opinion in Plant Biology, London, v.9, p.484-489, 2006.

SWAIN, M.S.; SINGH, D.P. Tall tales from sly dwarves: novel functions of gibberellins in plant development. Trends in Plant Science, London, v.10, n.3, 2005.

TOKUMOTO M.; TABEI Y, KAYANO, T.; OKU, H.; IWASAKI, H.; CHINEN, I. Adventitious embryogenesis and plantlet regeneration from ovules of unpollinated ovaries of papaya (Carica papaya L.) Journal of the Japanese Society for Horticultural Science, Okayama, v.69, n.2, p.195-201, 2000.

VREUGDENHIL, D.; BOOGAARD, Y.; VISSER, R.G.F.; BRUIJN, S.M. Comparison of tuber and shoot formation from in vitro cultured potato explants. Plant Cell Tissue and Organ Culture, Dordrecht, v.53, n.3, p.197-204, 1998. 